\title{
SACRAL LIPOMYELOCELE PRESENTING AS A HUMAN TAIL
}

Rajesh Raman, Geetha. M. J.

1. Assistant Professor. Department of Radiodiagnosis, JSS Medical College, Mysore.

2. Senior Resident. Department of Radiodiagnosis, JSS Medical College, Mysore.

\section{CORRESPONDING AUTHOR}

Dr. Rajesh Raman

47, Shankar Mutt Layout,

$4^{\text {th }}$ Cross, Fort Mohalla,

Mysore-570004.

E-mail: rajeshiyer81@gmail.com

Ph: 00919481822984

ABSTRACT: Spinal anomalies are commonly encountered in radiology practice. Spinal dysraphism is defined as a defect in the development and closure of the germ layers of the developing spine. It can manifest as a soft tissue mass in the spinal region or may remain occult without any visual mass. Sacral spina bifida usually presents as a globular soft tissue mass over the back. Its presentation as a tail like projection is rare and infrequently reported. Because of its rarity, such a case may be regarded as an anatomical variant resulting in neurological consequences in later life. The objective of this article is to sensitize the clinicians to the rare manifestation of sacral lipomyelocele as human tail.

KEY WORDS: Human tail; Spinal dysraphism; Lipomyelocele.

INTRODUCTION: Spinal anomalies are commonly seen in routine radiology practice. Sacral spina bifida is a type of spinal anomaly which may present either with or without a back mass. When present, the mass in the spinal region will be usually in the form of a globular swelling. Tail like presentation of the same is very rare. These patients may be clinically asymptomatic. The neurological features may manifest any time from birth to the age of 76 years ${ }^{1}$. Our patient presented with urinary incontinence and a tail like projection over the back at the age of 38 years. He was evaluated with MRI and the condition was diagnosed as sacral lipomyelocele with tethered cord. He underwent resection of the tail and release of the cord tethering with betterment of his symptoms. Even though the occurrence of spina bifida with lipomyelocele is a common entity, due to the rarity of its presentation as a human tail, the case is reported here.

CASE PRESENTATION: A 38 yr old man, a mason by occupation presented to the urology OPD with the complaint of incontinence of urine from past 3 years. He could not afford medical evaluation for 3 years due to financial constraints. He had a tail like projection at the back since birth. Physical examination revealed a skin covered tail like projection over the back, measuring approximately 8 inches in length and curved at its tip (Fig.1). The power of the muscles of the lower limb was normal. There was no history of any other neurological problems in him. The reproductive function of the patient was normal as he already had two children.

IMAGING FINDINGS: Plain radiographs of the L-S spine revealed sacral spina bifida spanning the entire sacrum. MRI of the lumbosacral spine was performed with a $1.5 \mathrm{~T}$ Siemens MRI system in prone position. It revealed sacral spina bifida. The tail like projection showed iso- 
hyperintense signal on T1 and hyperintense signal on T2 weighted sequences (Fig.2a \& 2b) with suppression of the signal on STIR sequence (Fig.2c) suggestive of fat signal intensity.

The spinal cord was low lying and tethered to the fat tissue. The nerve roots extended to the tail through the sacral defect. The skin over the tail was intact. The proximal spinal cord however showed normal signal intensity. There was no evidence of syrinx or tonsillar herniation in the proximal MRI sections.

A diagnosis of sacral spina bifida with lipomyelocele \& tethered cord was made. The patient underwent excision of the tail with release of the cord tethering. Dissected specimen of the tail confirmed the imaging findings (Fig.3). Chromosomal analysis of the patient revealed macro deletion of long arm of chromosome 8, 11 \& 17 (Fig.4). After the release of the cord tethering, the continence of urine improved significantly.

DISCUSSION: Spinal dysraphism is defined as the defect in the development and closure of the ectodermal, mesodermal or neuro ectodermal tissues of the spine. It may affect the functioning of the brain, bowel, bladder and limbs. Its incidence varies from 3-4.6 per 10,000 births in the USA The incidence has come down in the recent years with better prenatal detection and regular use of folic acid supplements during pregnancy².

Spinal dysraphism can present with a spinal region mass when it is called spina bifida manifesta and without a spinal region mass called spina bifida occulta. The presence of dimple over the back, tuft of hair or cutaneous haemangiomas may draw the attention of the clinician towards the presence of occult spinal dysraphism ${ }^{1}$. The spinal mass in spina bifida manifesta usually presents as a globular swelling. Presentation of the mass as a tail is very unusual.

When a tail like projection is seen in a human being, it becomes necessary to differentiate whether it is a true tail or a pseudo tail. A true tail consists of fat, fibrous tissue, muscle fibers, blood vessels, skeletal tissue and nerve fibers. It is covered by skin. The "pseudo tail" contains all these structures along with bone, cartilage, notochord and spinal cord. Spinal dysraphism may be seen in both the conditions ${ }^{13}$.

According to Fallon et al, tail is a prominent feature in the human embryo and contains primitive notochord and the gut. As the cell division continues, the cells in the tail start dying. The death of the cells in the tail starts by stage 17 of cell division and completes by stage 22 . No tail is observable after stage 22 of human cell division. Hence persistence of the tail after this stage is abnormal ${ }^{3}$.

Clinical features in patients with tail like spinal dysraphism include reduced muscle power of the lower limbs, gait disturbances, decreased perianal sensation ${ }^{4}$, bowel \& bladder dysfunction 5 , back ache, numbness in the lower limbs etc. Associated anomalies like club foot and renal anomalies are seen in about $2 \%$ of cases ${ }^{1}$. Association with VATER group of anomalies is also well known 6 . Our patient did not have any such associated anomaly.

The patients of spinal dysraphism usually present at an average age of 3 years with neurological dysfunction. However a wide range of presentation from birth to 76 years of age has been reported ${ }^{1}$ Our patient presented at an age of 38 years with incontinence of urine. Venkataramana et al have reported a case of tail at 26 years of age ${ }^{5}$. Most of the literature on human tails with spinal dysraphism is in the pediatric age group only.

Complications of tail like spinal dysraphism include neurological deficits, incontinence of urine \& feces, impotence, secondary complications of neurogenic bladder etc. A very rare complication of rhabdomyosarcoma has been described in a case of lipomyelocele by A.M. O'Connell et al7. 
Imaging modalities like plain radiography, computed tomography and MRI are used in the evaluation of spinal dysraphism. Conventional myelography and CT myelography even though useful diagnostically, are not frequently performed in the current era due to their invasive nature and better spatial resolution offered by the MRI ${ }^{8}$. Santiago Medina et al evaluated 101 patients with spinal dysraphism using fast MRI sequences. According to their study, the diagnostic accuracy of MRI was excellent in evaluating the spinal dysraphism using fast MRI sequences. MRI also had the advantage of adequately displaying the anatomy of the retroperitoneum excellently so that associated renal anomalies could be assessed along with the spinal anomaly. The tethering of the cord, abnormal signal intensity in the cord and secondary changes in the cord were all better delineated by the MRI than any other modality9.

Fat signal intensity back mass on MRI with suppression of signal on fat saturated sequences in a case of spina bifida is suggestive of lipomyelocele. Most of the spinal region masses in a study of a series of 97 children by Hoffman et al were fatty. The fat signal intensity may vary according to the other components in the mass. As there was intermingled neural tissue with in the mass, the tail in our case showed iso-hyperintense signal on T1 weighted images. The tail itself as a cause of cord tethering is infrequently seen and only four cases have been reported so far ${ }^{10}$. Mohindra et al have described a case of tail in the neck region causing cord tethering ${ }^{11}$. In our case too, tethering was due to the human tail.

Sepulweda et al have described chromosomal anomalies in fetuses with open neural tube defects on prenatal ultrasound. They have come across Trisomy 18 and Trisomy 13 as the commonest anomalies ${ }^{12}$. In our patient, there were macro deletions of chromosome $8,11 \& 17$. Sparse literature is available on this type of chromosomal abnormality with spinal dysraphism.

Human tail is almost always associated with spina bifida. Early prompt diagnosis is important as the release of the cord tethering may reduce the possible complications in the future and prevent disability. Thus, any case presenting with a tail at the back should not be ignored owing to the absence of clinical features in the childhood. Such patients should be thoroughly investigated with spinal MRI and treated as early as possible.

\section{BIBLIOGRAPHY:}

1. Tavafoghi V, Ghandchi A, Hambrick GW Jr, Udverhelyi GB. Cutaneous signs of spinal dysraphism. Arch Dermatol.1978;114:573-7.

2. Jorde LB, Fineman RM, Martin RA. Epidemiology of neural tube defects in Utah. Am J Epidemiol.1984; 119:487-95.

3. Fallon, J.F, Simadl B.K. Evidence of a role of cell death in the disappearance of the embryonic human tail. American Journal of Anatomy. 1978;152(1):111-29.

4. Narasimhachari Raghavan, A. James Barkovich, Michael Edwards, David Norman. MR imaging in the tethered spinal cord syndrome. American Journal of Radiology.1989 April; 152:843-52.

5. N. K. Venkataramana, Shailesh A.V. Rao, Arun L. Naik, Neeraj Awasthy, H. Gupta, Kramchand Sharma. The tale of a tail. J. Paed neurosciences.2008; 3: 142-145.

6. Jose Murillo B. Netto, Andre N. Bastos, Andre A. Figueiredo, Luis M. Perez. Spinal dysraphism: A neurosurgical review for the Urologist. Reviews in Urology. 2009; 11: 71-81.

7. A.M. O'Connell, D. Allcutt, F. Brett, S. Ryan. Malignant transformation of lipomyelocele into a rhabdomyosarcoma. AJNR.2008 March; 434-35. 
8. James H. Scatliff, Brian E. Kendall, Derek P.E. Kingsley, Juliet Britton, D. Norman Grant, Richard D. Hayward.Closed spinal dysraphism: Analysis of clinical, radiological and surgical findings in 104 consecutive patients. American Journal of Radiology.1989 May; 152: 1049-57.

9. Santiago Medina, May Al- Orfali, David Zurakowski, Tina Young Poussaint, James Dicanzio, Patrick D. Barnes. Occult lumbo sacral dysraphism in children and young adults:Diagnostic performance of Fast screening and conventional MR imaging. Radiology.1999; 211:767-71.

10. Hoffman, Taecholarn C, Hendrick EB, Humphreys RP. Management of lipomyelomeningoceles. J Neurosurg.1985; 62:1-8.

11. S Mohindra. The human tail causing tethered cervical cord. Spinal Cord. 2007; 45: 58385.

12. Sepulweda.W, Corral E, Ayala C, Be C, Gutierrez J, Vasquez P. Chromosomal abnormalities in fetuses with open neural tube defects: prenatal identification with ultrasound. Ultrasound Obstet Gynecol. 2004 Apr;23(4):352-56.

13. Biswanath Mukhopadhyay, Ram M. Shukla, Madhumita Mukhopadhyay, Kartik C. Mandal, Pankaj Haldar, Abhijit Benare. Spectrum of human tails: A report of six cases. J Indian Assoc Pediatr Surg.2012;17(1): 23-25.

Figure.1: Photograph of the back of the patient showing skin covered tail like projection curved at its tip.

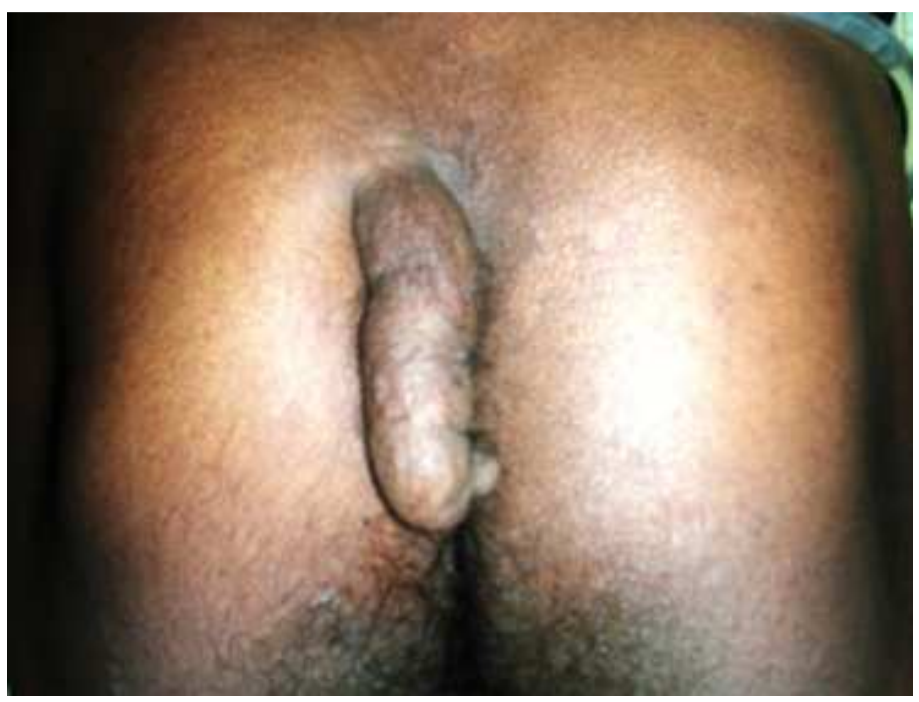


Figure. 2A , 2B \& 2C: T1 weighted sagittal image showing hyperintense tail at the back (2A). Sagittal T2 weighted image showing hyperintense signal in the tail (2B). STIR sagittal image showing suppression of the hyperintense signal suggestive of fat $(2 \mathrm{C})$.

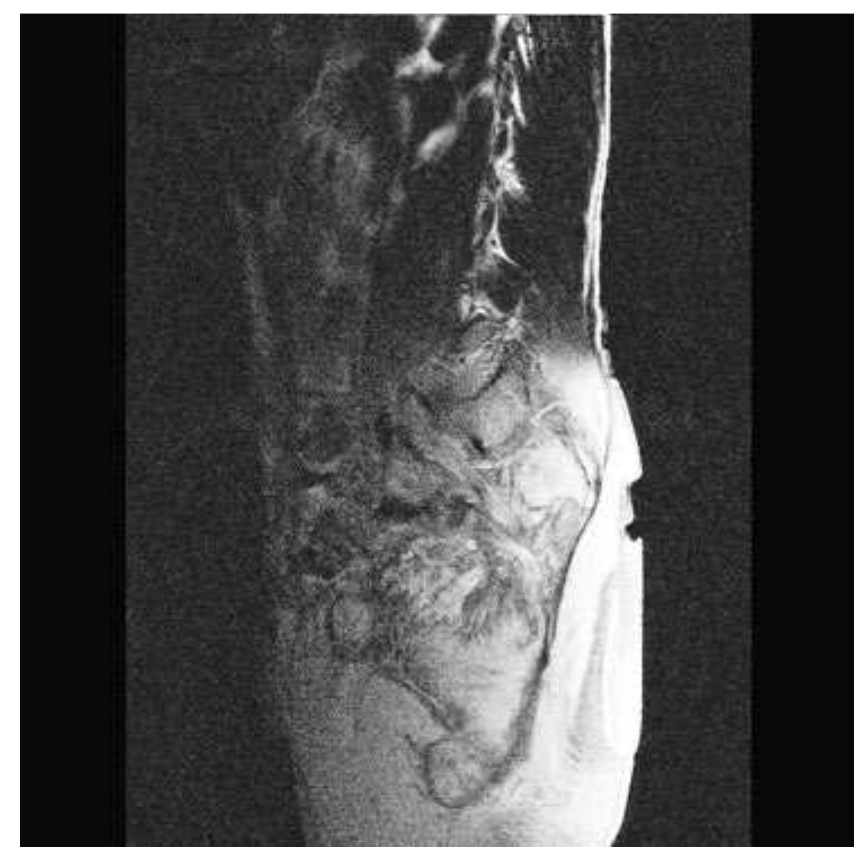

Fig 2A

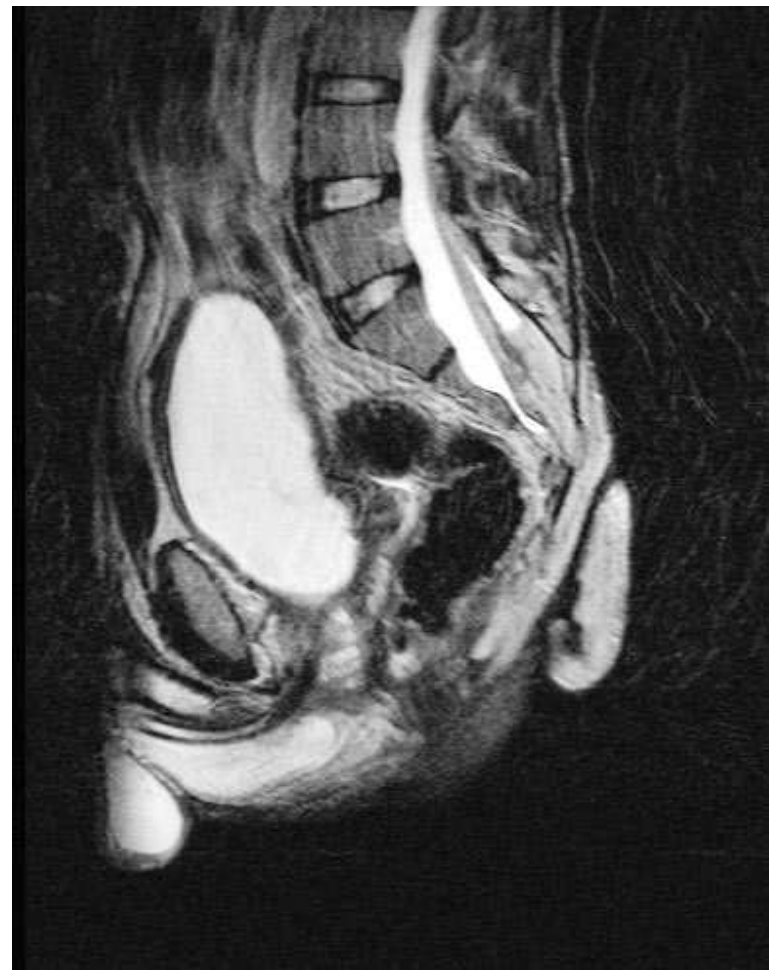

Fig 2B 


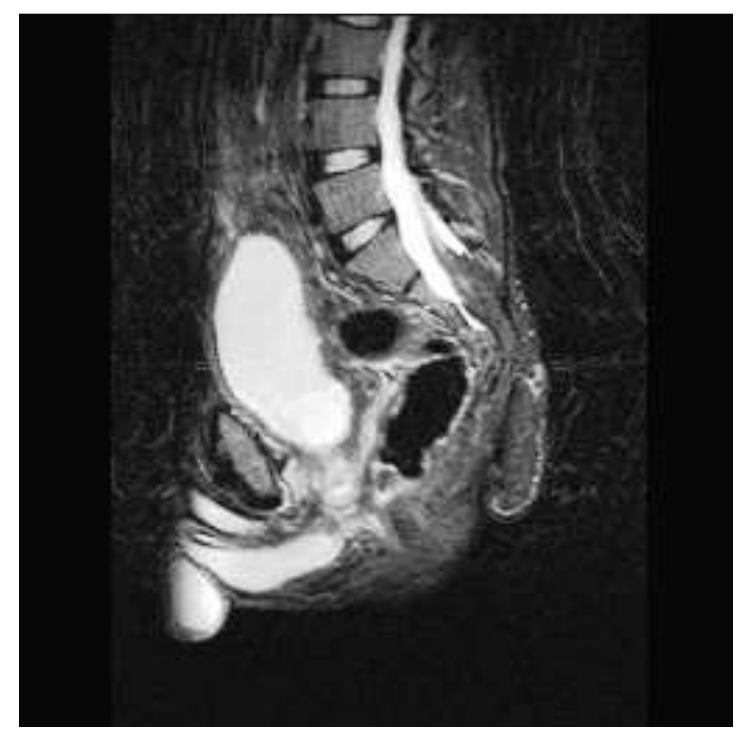

Fig 2C

Fig. 3: Dissected surgical specimen of the tail showing intact skin and presence of fat. No bone was seen.

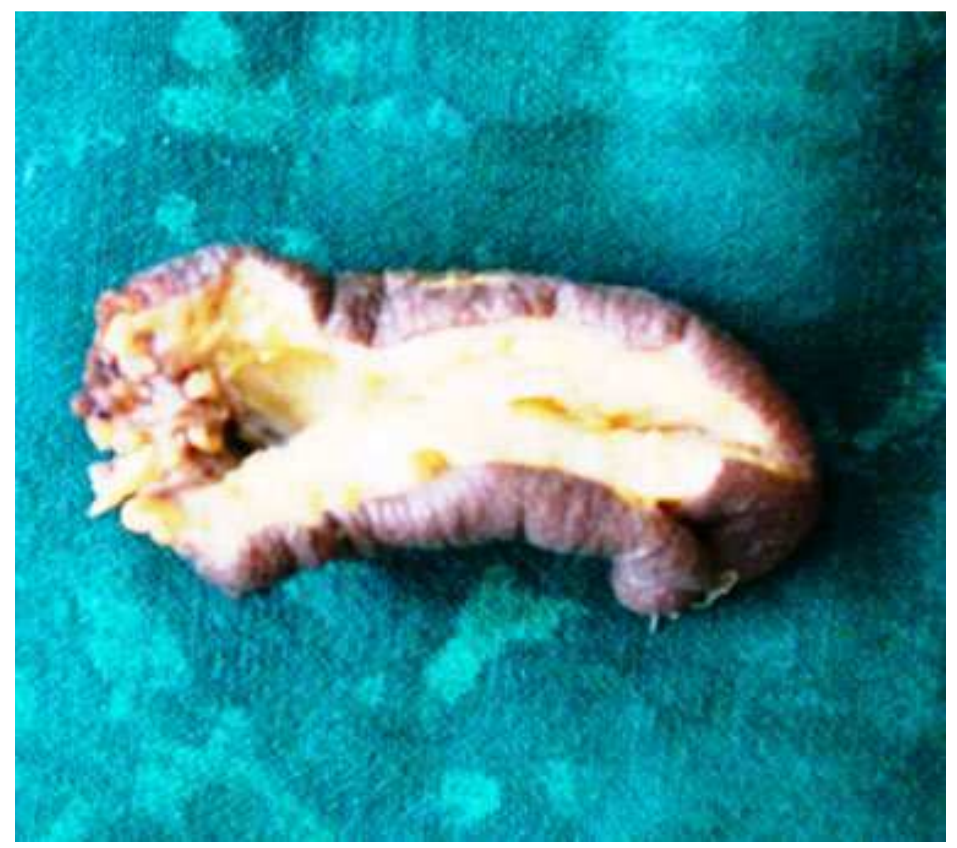


Fig.4: Photograph of the chromosomal analysis showing macro deletion of the long arms of chromosome 8, 11 \& 17 .

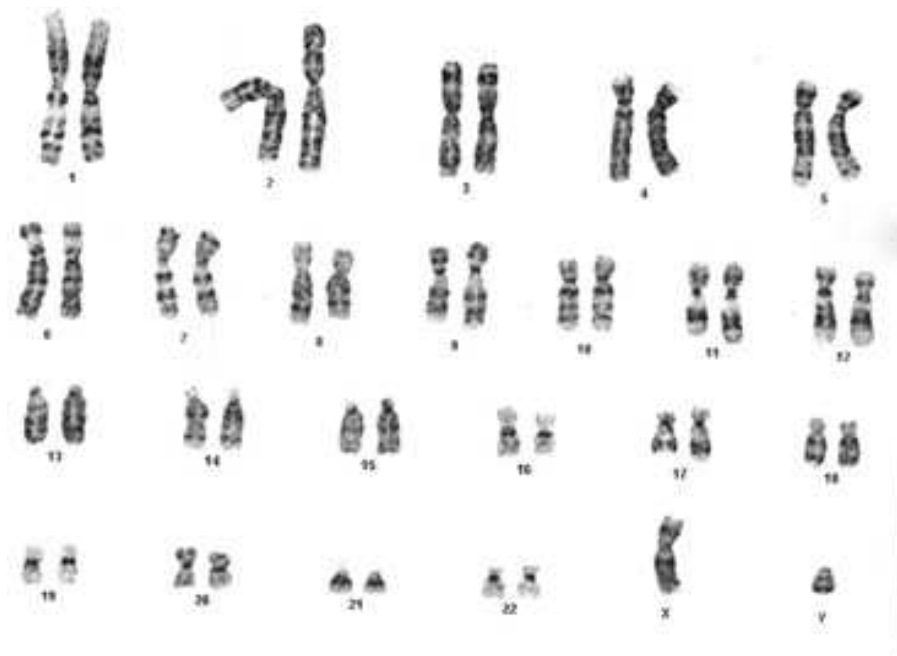

